REFLEKSI HUKUM

Jurnal Imu Hukum
p-ISSN 2541-4984 | e-ISSN 2541-5417

Volume 5 Nomor 2, April 2021, Halaman 179-198

DOI: https://doi.org/10.24246/jrh.2021.v5.i2.p179-198

Open access at: http:// ejournal.uksw.edu/refleksihukum

Penerbit: Fakultas Hukum Universitas Kristen Satya Wacana

\title{
TANTANGAN DAN STRATEGI PELAKSANAAN INDONESIA-AUSTRALIA COMPREHENSIVE ECONOMIC PARTNERSHIP AGREEMENT (IA-CEPA)
}

\section{Yafet Y.W. Rissy}

Fakultas Hukum Universitas Kristen Satya Wacana | yafet.rissy@uksw.edu

A R T I C L E I N F O
Article history:
Received
21 Agustus 2020
Revised
1 Desember 2020
Accepted
15 April 2021

Kata-kata Kunci:
IA-CEPA; investasi;
perdagangan; strategi;
tantangan.

\section{Keywords:}

IA-CEPA; investment; trade; strategy; challenge.

\begin{abstract}
Abstrak
Indonesia-Australia Comprehensive Economic Partnership Agreement (IA CEPA) telah berlaku efektif 5 July 2020. Artikel ini menyorot tujuan dan substansi IA-CEPA, mengulas tantangan keberadaan model free trade agreement in casu IA-CEPA dan memberikan tawaran strategi bagi Indonesia dalam pelaksanaan IA-CEPA. Secara umum, tujuan IACEPA adalah untuk mendorong peningkatan hubungan dagang, investasi, kerja sama ekonomi, kelancaran arus masuk dan keluar barang, jasa dan orang, termasuk penurun tarif hingga ke $0 \%$ dan penghapusan hambatan non-tarif lainnya. Tetapi dari pihak Indonesia, terdapat sejumlah tantangan fundamental yang perlu diselesaikan agar dapat menerima manfaat maksimal. Salah satu tantangan besar yang dihadapi Indonesia saat ini ialah besarnya defisit neraca perdagangan Indonesia terhadap Australia. Untuk mengatasi isu ini, sejumlah strategi perlu dipertimbangkan antara lain implementasi konsep economic powerhouse, peningkatan skilled workers dan menghadirkan pendidikan vokasional berkualitas tinggi.
\end{abstract}

\begin{abstract}
The Indonesia-Australia Comprehensive Economic Partnership Agreement (IA CEPA) has been entered into force on July 5, 2020. This article examines the objectives and substance of the IA-CEPA, scrutinizes the challenges of the IA-CEPA free trade agreement model, and offers several strategies for Indonesia in implementing the IACEPA. In general, the objectives of the IA-CEPA are to promote the enhancement of trade, investment, economic cooperation, the smooth flow of goods, services, and people, including reducing tariffs to zero (0)\% and eliminating other non-tariff barriers. On the Indonesian side, however, there are a number of fundamental challenges that need to be resolved in order to gain the maximum benefits. One of the major challenges facing Indonesia today is the large trade deficit towards Australia. To overcome this issue, a number of strategies need to be considered such as implementing the economic powerhouse concept, increasing skilled workers, and providing high-quality vocational education.
\end{abstract}




\section{PENDAHULUAN}

Setelah melalui masa perundingan hampir tujuh tahun, akhirnya Menteri Australia dan Menteri Perdagangan Indonesia menandatangai Indonesia-Australia Comprehensive Economic Partnership Agreement (IA-CEPA) pada tanggal 4 Maret 2019 di Jakarta. Jelang setahun kemudian, tepatnya tanggal 7 Februari 2020, Indonesia telah mensahkan IA-CEPA melalui Undang-Undang (UU) No. 1 Tahun 2020 tentang Pengesahan Persetujuan Kemitraan Ekonomi Komprehensif Indonesia-Australia (Indonesia-Australia Comprehensive Economic Partnership Agreement). ${ }^{1}$ Sementara itu, Parlemen Australia telah terlebih dahulu meratifikasi IA-CEPA pada 26 November 2019, IA-CEPA berlaku efektif 5 Juli 2020.

Sebagai sebuah perjanjian dagang dan ekonomi bilateral khusus yang cakupannya sangat komprehensif, IA-CEPA perlu mendapatkan perhatian serius dari berbagai kalangan: pemerintah (pusat dan daerah), pengusaha, organisasi kamar dagang dan organisasi bisnis sektoral, termasuk kalangan universitas, dilaksanakan dengan sungguh agar tidak menjadi sekedar perjanjian dagang yang mubazir. Persoalan utamanya ialah apakah tantangan utama yang dihadapi Indonesia terkait pelaksanaan IA-CEPA? Masalah berikutnya ialah strategi atau kebijakan apakah yang perlu dilakukan Indonesia untuk mencapai tujuan pelaksanaan IA-CEPA?

Artikel ini dimaksudkan untuk menjawab kedua persoalan utama di atas. Namun sebelum mengurai lebih lanjut kedua isu penting di atas, Penulis akan memulai terlebih dahulu mengulas tujuan dan substansi IA-CEPA. Pembahasan selanjutnya terkait tantangan, manfaat teoritis dan praktis, termasuk sisi negatif dari berbagai free trade agreements termasuk IA-CEPA, serta memberikan sejumlah tawaran strategi yang perlu ditempuh Indonesia sehingga dapat memperoleh manfaat maksimal dari pelaksanaan IA-CEPA. Bagian akhir dari artikel ini memaparkan kesimpulan dan saran bagi pihak terkait (pemerintah dan swasta) terkait pelaksanaan IA-CEPA.

\section{PEMBAHASAN}

\section{Tujuan dan Substansi IA-CEPA}

Secara singkat dapat dikatakan bahwa tujuan IA-CEPA 2020 adalah untuk meningkatkan hubungan dagang antara Indonesia dan Australia secara lebih efisien dan transparan dengan menghilangkan hambatan tarif dan non-tarif atas barang dan jasa dari kedua negara untuk mendorong pertumbuhan perdagangan dan investasi dan kerja sama ekonomi antara kedua negara.

Tujuan rinci IA CEPA dirumuskan oleh Department of Foreign Affairs and Trade Australia of Australia dalam Artikel Indonesia - Australia Comprehensive Economic Partnership Agreement (IA-CEPA): Economic Cooperation Program (ECP) (Artikel 1.2 IA-CEPA 2020)2 yang substansinya adalah untuk a) mempromosi iklim bisnis dapat

\footnotetext{
$1 \quad$ Undang-Undang Nomor 1 Tahun 2020 tentang Pengesahan Persetujuan Kemitraan Ekonomi Komprehensif Indonesia-Australia (Indonesia-Australia Comprehensive Economic Partnership Agreement).

2 Department of Foreign Affairs and Trade Australia of Australia, 'Indonesia - Australia Comprehensive Economic Partnership Agreement (IA-CEPA): Economic Cooperation Program
} 
diprediksi, transparan dan konsisten demi peningkatan efisiensi ekonomi dan pertumbuhan perdagangan dan investasi; b) secara progresif meliberalisasi dan memfasilitasi perdagangan barang melaui penghapusan hambatan tarif dan nontarif; c) secara progresif meliberalisasi dan memfasilitasi perdagangan jasa dengan menghapus pembatasan dan tindakan diskriminatif dalam perdagangan jasa; d) menciptakan iklim investasi kompetitif untuk meningkatkan peluang investasi melalui promosi, perlindungan, fasilitasi dan liberalisasi investasi; e) mempromosikan penggunaan elektronik bisnis (e-commerce) dalam perdagangan dan investasi; f) mempromosikan persaingan, efisiensi ekonomi, kesejahteraan konsumen dan mitigasi praktik persaingan usaha tidak sehat; g) mempromosikan kerjasama ekonomi untuk memanfaatkan dan melaksanakan perjanjian ini dengan efektif dan efisien; dan h) memfasilitasi dan mempromosi prosedur perdagangan yang efisien dan transparan yang mempercepat pergerakan, pelepasan dan pengecekan barang untuk mengurangi biaya dan memastikan prediktabilitas bagi importir dan eksportir (terkait prosedur bea cukai/customs).

Tentu cakupan IA-CEPA, sesuai namanya sangat komprehensif (luas). Cakupan kerjasama ini sebenarnya sudah terlihat dalam rumusan tujuan dalam Artikel 1.2 IA-CEPA 2020 di atas. Cakupannya pengaturannya diawali dengan pengaturan perdagangan barang yang diatur dalam chapter 2, diantaranya diatur soal pengurangan dan penghapusan tarif (hingga 0\%), bea cukai dan subsidi ekspor dan pemberlakuan prinsip Most Favoued Nation Treatment dan prinsip National Treatment dan pengaturan asal barang. Untuk diketahui sejauh ini Australia mengeliminasi 100 persen atau semua pos tarifnya yakni 6,474 pos tarif menjadi 0 persen. ${ }^{3}$ Sementara itu, Indonesia mengeliminasi $94,6 \%$ dari seluruh total pos tarif berjumlah 10.813 pos tarif menjadi $0 \% 4$ Artinya arus barang masuk dan keluar (ekspor dan impor) kedua negara tidak lagi (atau sangat minimum) dikenakan tarif bea masuk.

Selanjutnya IA-CEPA mengatur mengenai ukuran non-tarif dalam chapter 3, diantaranya diatur mengenai mekanisme dan pembatasan jumlah non-tarif, dan lisensi import. Ketiga, pengaturan ketentuan asal barang atau rules of origin dalam chapter 4, diantaranya mengatur asal barang, barang yang sebagian atau seluruhnya diproduksi, formula perhitungan nilai barang dan de minimis rule, preferensi perlakuan tarif dan penolakannya, dokumentasi bukti barang dan pengecualiannya, kerjasama verifikasi, kerahasiaan asal barang dan pembentukan Sub Komite Asal Barang. Untuk diketahui Menteri Perdagangan baru saja mengeluarkan Permendag No. 3 Tahun 2020 tentang Perubahan Atas Peraturan Menteri Perdagangan No. 110 Tahun 2018 tentang Ketentuan Impor Besi Atau Baja,

(ECP)' (Department of Foreign Affairs and Trade Australia of Australia, May 2020) <https://www.dfat.gov.au/sites/default/files/investment-design-ia-cepa-ecp-may-2020-webvers.pdf> diakses 10 Juli 2020.

3 Kementerian Perdagangan Republik Indonesia 'IA-CEPA Lampiran 2-A Jadwal Komitmen Tarif Australia' (Direktorat Jenderal Perundingan Perdagangan Internasional 2020) <http:/ /ditjenppi.kemendag.go.id/assets/files/publikasi/doc_20191203_2a-australia-tariffschedule-bahasa.pdf> diakses 10 Juni 2020.

$4 \quad$ Kementerian Perdagangan Republik Indonesia 'IA-CEPA Lampiran 2-A Jadwal Komitmen Tarif Indonesia' (Direktorat Jenderal Perundingan Perdagangan Internasional 2020) <http://ditjenppi.kemendag.go.id/assets/files/publikasi/doc_20191203_2a-indonesia-tariffschedule-bahasa.pdf> diakses 10 Juni 2020. 
Baja Paduan, dan Produk Turunannya ${ }^{5}$ untuk memudahkan arus masuknya barang besi, baja dan produk turunannya.

Selanjutnya, diatur khusus soal prosedur kepabeanan (customs procedures) dalam chapter 5, meliputi antara lain prosedur kepabeanan dan fasilitasi perdagangan, kerjasama kepabeanan, pemberitahuan di muka terkait ketentuan asal barang, titik publikasi dan pencarian, mekanisme peninjauan kembali dan banding, pinalti, manajemen resiko, pembebasan barang, dan kerahasiaan, informasi dan teknologi.

Ketentuan mengenai fasilitasi perdagangan diatur dalam chapter 6 , pengaturannya antara lain meliputi titik publikasi dan pencarian terkait misalnya administrasi kuota tarif, asal barang untuk kepentingan importasi, prosedur, pembatasan dan larangan importasi dan eksportasi, barang masuk, dan transit, syarat barang yang diperbaiki dan masuk kembali, prosedur peninjauan kembali dan banding, ketentuan barang yang mudah rusak (perishable goods), penerimaan salinan dari barang import, eksport dan asal barang, dukungan bagi fasilitasi perdagangan dan pembentukan Sub Komite Fasilitasi Perdagangan.

Pengaturan selanjutnya terkait ukuran sanitasi dan fitosanitasi diatur dalam chapter 7 , yang meliputi pengaturan mengenai kesehatan sanitasi dan fitosanitasi (kesehatan tetumbuhan) terkait prinsip keseimbangan, adaptasi kondisi regional, kerjasama, transparansi dan pemberitahuan, konsultasi teknis, dan pembentukan Sub Komite Sanitasi dan Fitosanitari. Kemudian, terkait hambatan teknis perdagangan. Chapter 8 mengatur antara lain standar, aturan teknis, prosedur penilaian kesesuaian/kepatuhan, kerjasama, transparansi, konsultasi, pengaturan perjanjian dan pelaksanaannya, pihak yang bertanggungjawab untuk dihubungi (contact points), dan pembentukan Sub Komite Hambatan Teknis Dagang.

Perdagangan Jasa di atur dalam chapter 9, pengaturannya meliputi antara lain produksi, distribusi, pemasaran, penjualan dan pengantaran, pembelian, penggunaan dan pembayaran jasa, akses jasa publik, prosedur uang jaminan, akses pasar, ukuran ketidakpatuhan, pengakuan dan penolakan manfaat, keterbukaan, pembayaran dan transfer, peninjuan kembali, pemberlakuan prinsip Most Favoured Nation Treatment ${ }^{6}$ dan prinsip national treatment ${ }^{7}$ dan pembentukan Komite Perdagangan Jasa. Isu jasa keuangan di atur dalam chapter 10, pengaturannya antara mencakupi bank, asuransi, nilai tukar, peninjauan kembali, perlakuan dan pemrosesan informasi tertentu, organisasi self-regulatory, sistem pembayaran dan kliring, keterbukaan dan administrasi ukuran tertentu, dan penyelesaian sengketa dalam investasi jasa keuangan melalui arbitrasi, Investor State Dispute Settlement (ISDS) dan mekanismenya.

Ketentuan mengenai telekomunikasi diatur dalam chapter 11, yang pengaturannya meliputi jasa dan jaringan telekomunikasi dan pengaturan, akses dan penggunaan atas jasa dan jaringan telekomunikasi publik, kewajiban penyedia jasa dan jaringan telekomunikasi, perlakuan bagi penyedia besar jasa dan

5 Peraturan Menteri Perdagangan Republik Indonesia Nomor 03 Tahun 2020 tentang Perubahan Atas Peraturan Menteri Perdagangan Nomor 110 Tahun 2018 tentang Ketentuan Impor Besi Atau Baja, Baja Paduan, Dan Produk Turunannya.

6 Stephen Fietta, 'Most Favoured Nation Treatment And Dispute Resolution Under Bilateral Investment Treaties: A Turning Point?' (2005) 4 International Arbitration Law Review 131.

Emily Lydgate, 'Sorting Out Mixed Messages under the WTO National Treatment Principle: A Proposed Approach' (2016) 15 (3) World Trade Review 423. 
telekomunikasi publik, aturan anti persaingan usaha tidak sehat dalam jasa telekomunikasi, akses atas fasilitas penyedia besar jasa dan telekomunikasi publik, penjualan kembali, pengaturan dan harga jasa sirkuit yang disewakan oleh penyedia besar, kabel bawah laut internasional, badan pengaturan independen dan kepemilikan pemerintah, kewajiban jasa universal, proses lisensi, penggunaan dan alokasi sumber daya langka, penyelesaian sengketa telekomunikasi, dan keterbukaan.

Terkait pengaturan mengenai pergerakan orang diatur dalam chapter 12, meliputi prosedur permohonan, jaminan masuk sementara, perjalanan bisnis, ketentuan informasi terkait pergerakan orang dan penyelesaian sengketa Bidang cakupannya sangat luas yang bisa dilihat dalam Anex 12-A. Sedangkan pengaturan mengenai perdagangan elektronik atau E-commerce terdapat dalam chapter 13 yang meliputi kerjasama dan penggunaan e-commerce, autentikasi dan tanda tangan elektronik, perlindungan konsumen online, perlindungan informasi pribadi, kerangka pengaturan domestik, keterbukaan, transfer informasi lintas batas oleh alat elektronik, fasilitas lokasi penghitungan, dan sumber kode.

Secara khusus tema investasi diatur dalam chapter 14, pengaturannya meliputi standar minimum dan larangannya, pengaturan investor baik orang dan badan hukum, pemberlakukan prinsip Most Favoured Nation Treatment dan prinsip National Treatment, perlakukan dalam situasi konflik bersenjata dan konflik sosial, senior management dan dewan direktur, ekpropriasi dan kompensasi, subrogasi, penolakan manfaat, ukuran ketidakpatuhan, formalitas khusus dan pengungkapan informasi, corporate social responsibility, promosi tujuan pengaturan, dan pembentukan Komite Investasi.

IA-CEPA juga memberi perhatian besar bagi kerja ekonomi dalam Chapter 15, dimana terdapat skenario besar untuk mendukung dan memfasilitasi perdagangan dan investasi, pertumbuhan ekonomi dan kemakmuran dan pembentukan Komite Kerjasama Ekonomi. Akhirnya, Bab-Bab selanjutnya dari IA-CEPA. Chapter 16 hingga Chapter 21 lebih mengatur mengenai pengaturan mengenai persaingan usaha, ketentuan umum dan pengecualian, transparansi, konsultasi dan mekanisme penyelesaian sengketa, dan ketentuan penutup.

Dari uraian di atas, terlihat bahwa cakupan substansi IA-CEPA memang sangat luas. Namun secara garis besar dari aspek ekonomi dan kelembagaan, Penulis berpendapat, IA-CEPA dapat dikategorikan dalam lima kelompok besar yakni a) Perdagangan barang: penghapusan hambatan tarif, asal barang, kepabeanan, sanitasi dan fitosanitasi dan fasiliatasi perdagangan; b) Perdagangan jasa: jasa keuangan, telekomunikasi, pergerakan orang, dan jasa profesi lainnya; c) Investasi: perlindungan investasi dan investor dan kebijakan anti persaingan usaha tidak sehat dan mekanisme penyelesaian sengketa melalui Investor-State Dispute Settlement (ISDS); d) E-commerce atau perdagangan elektronik; digital platform untuk UMKM, perlindungan data pribadi dalam transaksi elektronik; dan cyber security issues; dan e) Kerjasama ekonomi umumnya: ketentuan kelembagaan dan kerangka kerja sama.

Jika di-breakdown lagi ke kerja sama per sektor IA-CEPA cakupannya juga cukup luas dan variatif mulai dari bidang a) pertanian seperti produk pertanian berupa susu, buahan, biji-bijian, kentang dan wortel, dan binatang hidup seperti sapi, domba dan produk beku dagingnya; b) pendidikan vokasi (antara lain 
pertanian, teknologi informasi, administrasi business, dll) dan paket keahlian (skill package) dimana Indonesia dan Australia memberikan kesempatan pelatihan enam (6) bulan tenaga kerja di berbagai bidang; c) telekomunikasi, jasa profesi seperti jasa perencanaan kota, arsitek, konstruksi, pemetaan, pendidikan tinggi (universitas dan sekolah vokasi) dan pelatihan; d) energy seperti pembangkit geothermal, instalasi dan konstruksi kelistrikan, pembangkit listrik lebih dari $10 \mathrm{MW}$ ), konstruksi gas dan minyak; e) manajemen air; f) transportasi seperti tol, jembatan, terowongan, g) jasa pertambangan seperti kontrak pertambangan dan persiapan tempat pertambangan; h) kesehatan seperti jasa rumah sakit besar, patologi, paramedic dan kesehatan gigi, dan i) pariwisata dimungkinkan kepemilikan hotel berbintang tiga, empat, dan lima, restoran dan bar, operator tour dan konsultasi kepariwisataan. ${ }^{8}$

Mengingat luasnya cakupan IA-CEPA maka pemerintah dan kalangan usaha perlu bergerak cepat untuk memastikan operasionalisasi dan implementasi dari berbagai ketentuan besar di atas.

\section{Tantangan dalam Pelaksanaan Free Trade Agreements: in casu IA-CEPA}

Indonesia sesungguhnya telah memiliki sejumlah free trade agreements baik regional, seperti Asean Free Trade Agreement (AFTA, 1992), ${ }^{9}$ The ASEAN AustraliaNew Zealand FTA (AANZFTA, 2009) ${ }^{10}$ maupun bilateral seperti Indonesia-Pakistan Preferential Trade Agreement (IP-PTA, 2019) ${ }^{11}$ dan Indonesia-Chile Comprehensive Economic Partnership Agreement (IC-CEPA, 2017). ${ }^{12}$ Namun hingga saat ini belum terlihat efektifitas dari berbagai perjanjian tersebut bagi Indonesia. ${ }^{13}$

Pada tahun 2020, IA-CEPA menambah satu lagi bilateral free trade agreement Indonesia. Apa nilai strategis IA-CEPA bagi kedua negara, khususnya bagi Indonesia? Secara teoritis, berbagai kerjasama dagang bilateral dan multilateral dapat menciptakan penghapusan tarif dan non-tarif yang bermuara pada penghematan tabungan cadangan devisa, memberi akses besar bagi pasar internal sehingga menciptakan persaingan di antara para pesaing. Besarnya akses pasar internal dapat menciptakan pula peluang pemanfaatan skala ekonomi melalui spesialisasi produksi. Bebasnya aliran barang dan jasa memungkinkan negara

8 Parliament of Australia. Report 186, ‘3. IA-CEPA Benefits' (Parliament of Australia 2009) <https://www.aph.gov.au/Parliamentary_Business/Committees/Joint/Treaties/IndonesiaAustraliaCEPA/Report_186> diakses 10 Juli 2020; lihat juga Ayman Falak Medina, 'Indonesia and Australia Ratify IA-CEPA Agreement' (ASEAN Briefing, 14 Februari 2020) <https://www.aseanbriefing.com/news/indonesia-australia-ratify-ia-cepa-agreement/> diakses 12 Juli 2020.

World Trade Law, 'ASEAN Free Trade Agreements (AFTA)' <http:/ / www.worldtradelaw.net/fta/agreements/afta.pdf.download> diakses 20 Juli 2020.

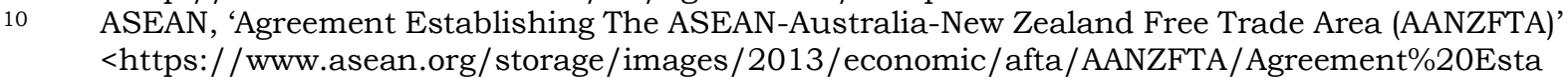
blishing\%20the\%20AANZFTA.pdf> diakses 10 Juli 2020.

11 Kementerian Perdagangan Republik Indonesia, 'Indonesia-Pakistan Preferential Trade Agreement' <https://e-ska.kemendag.go.id/uploads/lampiran_surat_IP_PTA.pdf> diakses 10 Juli 2020.

12 Kementerian Perdagangan Republik Indonesia, 'Chile - Indonesia Comprehensive Economic Partnership Agreement' < http://www.sice.oas.org/trade/CHL_IDN/CEPA_Index_e.asp > diakses 10 Juli 2020.

13 Vendy Yhulia Susanto, 'IA-CEPA berlaku, ekonom CORE berharap Indonesia bisa kerek ekspor ke Australia' (Kontan, 11 Juli 2020) <https://nasional.kontan.co.id/news/ia-cepa-berlakuekonom-core-berharap-indonesia-bisa-kerek-ekspor-ke-australia> diakses 12 Juli 2020. 
mengkapitalisasi keunggulan komparatif, dan karenanya mengoptimalkan alokasi sumber daya. ${ }^{14}$

Sebagai bagian dari bilateral free trade agreements, IA CEPA juga memiliki nilai strategik teoritis di atas. Persoalannya adalah apakah Indonesia mampu memaksimalkan berbagai peluang dan nilai strategik dari IA-CEPA sehingga mendatang kemakmuran? Atau sebaliknya apakah Indonesia akan menjadi semakin merana karena Indonesia akan semakin bergantung pada Australia dan terus mengalami defisit neraca perdagangan? Berada di bagian yang menguntungkan atau merugikan, sangat bergantung pada pilihan strategi implementasi IA-CEPA oleh Indonesia.

Selanjutnya, apa syaratnya agar Indonesia dapat memperoleh manfaat maksimal dari IA-CEPA? Secara teoritis, model free trade agreements apapun mensyaratkan kuatnya jaringan partisipasi umumnya dan situasi ini memberikan alasan bagi upaya peningkatan bangunan kapasitas (capacity building) dari sebuah negara. ${ }^{15}$ Dalam konteks IA-CEPA, adalah sangat penting bagi pemerintah Indonesia untuk memastikan adanya sinergi antara jaringan nasional dan sumber daya nasional baik itu dari kalangan swasta (pengusaha, asosiasi dagang, perguruan tinggi, usaha kecil, menengah dan besar) dan publik (pemerintah) dan pentingnya berbagi sumber daya dengan efektif (effective resources sharing) dalam negeri agar dapat meningkatkan partisipasi Indonesia dalam implementasi IA-CEPA.

Sedangkan dari sisi empirik free trade agreements antara berbagai negara (bilateral, regional dan multilateral) telah terbukti membawa perbaikan kondisi pabrik khususnya textile (Amerika-Kamboja), peningkatan lapangan kerja, pertukaran informasi, data, teknologi dan pengetahuan (Kanada dan Chile, 2004), menyediakan mekanisme penyelesaian sengketa dagang yang damai (Amerika dan Chile, 2004), dan bahkan meningkatkan partisipasi publik dalam isu-isu yang relevan dengan perdagangan (Kanada dan Peru, 2009). ${ }^{16}$

Manfaat potensial teoritik dan empirik di atas (lihat juga pengalaman Singapore dalam pembahasan di bawah) sama sekali tidak menegasi adanya fakta bahwa free trade agreement bisa juga menimbulkan dampak negatif. Karenanya, IA-CEPA, terlepas dari tujuan mulianya untuk meningkatkan perdagangan barang dan jasa tanpa ataupun dengan hambatan minimal antara Indonesia dan Australia, kiranya perlu diingat IA-CEPA bisa atau berpotensi menciptakan eksternalitas negatif, di antaranya seperti pembajakan piranti lunak (software), ${ }^{17}$ meningkatkan ketidakadilan upah seperti yang dialami Amerika terhadap China ${ }^{18}$ ataupun yang dilakukan negara maju atas negara berkembang ${ }^{19}$ dan berpindahnya industri yang

14 Teofilo C. Daquila and Le Huu Huy. 'Singapore and ASEAN in the Global Economy, The Case of Free Trade Agreements’ (2003) 43 (6) Asian Survey 908, 912.

15 Inge Kaul Isabelle Grunberg Marc A. Stern (eds.), Global public goods: international cooperation in the 21st century (UNDP Oxford University Press 1999) xxxv.

16 Karin Lukas and Astrid Steinkellner, Social Standards in Sustainability Chapters of Bilateral Free Trade Agreements (Ludwig Boltzmann Institute of Human Rights 2010) 3-7.

17 Amy R. Edge, 'Preventing So ware Piracy through Regional Trade Agreements: A Mexican Example' (1994) 20 (1) North Carolina Journal of International Law and Commercial Regulation 175, 175.

18 Robert E. Scott, Unfair trade deals lower the wages of U.S. workers (Economic Policy Institute, Washington DC 2015) 1-2.

19 Ronald D. Fischer and Pablo Serra, Income Inequality and Choice of Free Trade in a Model of Intra-industry Trade' (1999) 111 (1) The Quarterly Journal of Economics 41, 45. 
kotor dari negara maju ke negara berkembang, ${ }^{20}$ dan eksternalitas koordinasi dimana negara berkembang (termasuk Indonesia) tidak mampu mengambil manfaat dari negara maju. ${ }^{21}$

Dalam konteks IA-CEPA, terdapat peluang terjadi negatif eksternalitas seperti digambarkan di atas. Bisa saja terjadi kondisi dominasi barang dan jasa dari Australia ke Indonesia yang bisa memicu persoalan baru berupa ekses negatif bagi masyarakat lokal yang memproduksi barang dan jasa yang sejenis dan defisit perdagangan yang makin mendalam. Mengapa? hal disebabkan karena di satu sisi tarif masuk barang dan jasa menjadi minimal bahkan nol dan karenanya pendapatan negara berkurang. Konsekuensi lanjutannya ialah pangsa pasar domestik malah diambil alih atau didominasi oleh produk dan jasa Australia sehingga bisa menciptakan pengangguran dan lambatnya ekonomi lokal. Bahkan dari aspek sosial dan politik, kondisi seperti ini bisa menggerus kepercayaan publik domestik bagi barang dan jasa buatan Indonesia dan bisa menciptakan ketidakstabilan sosial, ekonomi dan politik. Jika ini skenarionya maka Indonesia tidak bisa mengambil manfaat maksimal dari Australia (eksternalitas koordinasi).

Oleh karena itu, tugas pemerintah adalah untuk memastikan bahwa Indonesia bisa mendapatkan manfaat maksimal dari IA-CEPA tetapi di saat bersamaan berpikir sejak awal untuk mengantisipasi dan memitigasi potensi eksternalitas negatif dari IA-CEPA sebagaimana diuraikan di atas. Tantangan besar lainnya bagi pemerintah Indonesia dari aspek hukum nasional ialah mempercepat harmonisasi hukum nasional yang terkait dengan persaingan usaha tidak sehat, investasi, imigrasi khususnya lintas masuk barang, jasa dan orang, penyesuaian regulasi tarif terkait produk dan jasa yang disepakati, dan pengaturan lebih lanjut mengenai sengketa investasi antara investor dan negara, termasuk harmonisasi hukum terkait pendidikan tinggi dan vokasi. Harmonisasi ini penting untuk menghindari konflik hukum nasional dengan substansi Perjanjian IA-CEPA. Jika harmonisasi berbagai hukum nasional di atas tidak terjadi atau lambat, maka dikuatirkan akan memperlambat daya gerak Indonesia untuk mengambil manfaat maksimal dari perjanjian IA-CEPA dan sekaligus dapat menggerus kepercayaan investor asing (khususnya dari Australia) atas konsistensi regulasi dan iklim investasi di Indonesia.

\section{Tawaran Strategi atas Implementasi IA-CEPA}

Di bagian ini, Penulis ingin memberikan sejumlah masukan praktis strategis berupa kebijakan dan strategi yang perlu ditempuh pemerintah, pengusaha dan universitas untuk sekiranya dipertimbangkan, dan lebih bagus lagi jika berguna dan dilaksanakan.

Pemerintah pusat perlu memposisikan diri sebagai leader, facilitator dan motivator, bertindak visioner, strategik dan konsisten. Perjanjian apapun bidangnya, tentu diinisiasi dan disetujui pemerintah. Oleh karenanya pemerintah, sekali lagi, perlu tampil proaktif dan strategik dalam memimpin dan mengkoordinasikan semua isu dan elemen yang terkait dan terlibat dalam pelaksanaan IA CEPA. Fasilitasi dan

20 P. Low and Yeats A., Do 'Dirty' Industries Migrate? in Patrick Low, ed., International Trade and the Environment; World Bank Discussion Papers (Washington, DC: World Bank 1992) 89, 103.

$21 \quad$ Nuno Limao and Kamal Saggi, 'Size Inequality, Coordination Externalities And International Trade Agreements' (2013) 63 European Economic Review 10, 27. 
dorongan pemerintah Indonesia sangat penting bagi kalangan usaha/pengusaha dan semua pihak terkait lainnya untuk mengkonsolidasikan kekuatan demi mencapai keuntungan maksimal dari pelaksanaan IA-CEPA. Dengan kata lain, ketiadaan fasilitasi dan dorongan pemerintah yang terstruktur dan sistematis hanya akan membuat Indonesia kalah atas Australia dalam persaingan investasi, ekspor barang dan jasa.

Singapore adalah contoh yang baik untuk persoalan leadership dan free trade. Singapore telah sejak lama menjadi pelopor free trade agreements tidak hanya dikalangan ASEAN, tetapi meluas di wilayah Asia dan Pasifik (APEC), memiliki FTA dengan Jepang, New Zealand, Australia, Eropa, Amerika dan masih banyak lagi di kawan Asia dan Amerika Utara. Jika Singapore saat ini menjadi salah satu negara dengan pertumbuhan ekonomi yang stabil (kecuali karena situasi pandemic Covid19 dimana pertumbuhan ekonomi global mengalami kontraksi dan menjadi salah satu negara maju dalam bidang ekonomi yang memiliki pendapatan per kapita yang tinggi (US \$ 65.233) ${ }^{22}$ atau urutan 9 di dunia di tahun 2019) itu tidak terlepas dari peran proaktif pemerintah Singapore dalam membuat, mengawal dan melaksanakan secara konsisten berbagai FTAs yang ditandatanganinya, mendorong foreign direct investment (FDI) dan kebijakan industrialisasi berorientasi luar (outward-oriented industrialization policy). 23

Sementara itu, bagi kalangan pengusaha, tentu baik secara mandiri maupun atas fasilitasi pemerintah pusat, perlu mempertimbangkan sejumlah langkah. Pertama, kalangan pengusaha perlu secara cermat mengidentifikasi kekuatan dan sektor unggulan (industri, jasa dan komoditas: pertanian, perikanan, kehutanan dll) dan fokus pada fasilitasi kalangan pengusaha untuk melakukan ekspor atau peningkatan proses produksi untuk menciptakan nilai tambah (added value). Masukan ini didasarkan pada fakta bahwa berdasarkan data Kementerian Perdagangan Republik Indonesia di tahun 2018, produk ekspor unggulan Indonesia ke Australia ialah 'minyak bumi senilai USD636,7 juta; kayu dan furnitur senilai USD2 14,9 juta; panel LCD, LED, dan panel display lainnya senilai USD100,7 juta; alas kaki senilai USD96,9 juta; serta ban senilai USD 61,7 juta. ${ }^{24}$ Jika sektor unggulan ini digenjot efisiensi dan produksinya tentu akan membantu mengurangi defisit neraca perdagangan Indonesia terhadap Australia.

Berdasarkan data dari Kementerian Perdagangan Republik Indonesia (Tabel 1), ${ }^{25}$ Indonesia mengalami defisit neraca perdagangan satu dekade terakhir (2012Mei 2019). Untuk tahun 2018 Indonesia mengalami defisit neraca perdagangan terhadap Australia yang sebesar US \$3,007 miliar, artinya Indonesia mengimpor

22 World Bank, 'GDP per capita (current US\$) - Singapore' (The World Bank, 1999) <https://data.worldbank.org/indicator/NY.GDP.PCAP.CD?locations=SG> diakses 10 Juli 2020.

23 Daquila and Huy (n 14) 919-910. Usaha' (Kementerian Perdagangan Republik Indonesia, 24 Oktober 2019) <https://www.kemendag.go.id/id/newsroom/media-corner/penyelesaian-ia-cepa-perludisambut-pelaku-usaha-1> diakses 10 Juli 2020.

25 Kementerian Perdagangan Republik Indonesia dalam Hafidz Arfandi and Rachmi Hertanti. 'Analisis Kritis Kerjasama Indonesia-Australia CEPA: "Berpotensi Besar Meningkatkan Impor, Ketimbang Ekspor"' (Indonesia for Global Justice 2019) 2 < http://igj.or.id/wpcontent/uploads/2019/08/Kertas-Kebijakan-IGJ_Juli-2019_IA-CEPA-1.pdf> diakses 10 Juli 2020. 
produk migas dan non migas yang lebih besar dari Australia (US \$ 5,829 milliar) dibandingkan dengan ekspor ke Australia (US \$ 2,819 miliar).

Tabel 1 -Neraca Perdagangan Indonesia-Australia 2012-2018 (Juta US\$)

\begin{tabular}{|l|r|r|r|r|r|r|r|r|r|}
\hline \multicolumn{1}{|c|}{ Uraian } & \multicolumn{1}{c|}{2011} & \multicolumn{1}{c|}{2012} & \multicolumn{1}{c|}{2013} & \multicolumn{1}{c|}{2014} & \multicolumn{1}{c|}{2015} & \multicolumn{1}{c|}{2016} & \multicolumn{1}{c|}{2017} & \multicolumn{1}{c|}{2018} & $\begin{array}{c}\text { 2019 } \\
\text { (Jan-Mei) }\end{array}$ \\
\hline TOTAL PERDAGANGAN & 10,760 & 10,203 & 9,409 & 10,595 & 8,518 & 8,469 & 8,532 & 8,644 & 2,980 \\
\hline MIGAS & 2,508 & 1,766 & 1,606 & 1,408 & 851 & 1,270 & 1,547 & 1,321 & 351 \\
\hline NON MIGAS & 8,252 & 8,437 & 7,803 & 9,187 & 7,667 & 7,199 & 6,985 & 7,323 & 2,629 \\
\hline EKSPOR & 5,582 & 4,905 & 4,370 & 4,947 & 3,701 & 3,208 & 2,524 & 2,819 & 883 \\
\hline MIGAS & 2,504 & 1,547 & 1,397 & 1,251 & 707 & 538 & 582 & 656 & 91 \\
\hline NON MIGAS & 3,078 & 3,358 & 2,973 & 3,696 & 2,994 & 2,670 & 1,942 & 2,163 & 791.6 \\
\hline IMPOR & 5,177 & 5,297 & 5,038 & 5,646 & 4,815 & 5,260 & 6,009 & 5,826 & 2,098 \\
\hline MIGAS & 3 & 219 & 209 & 156 & 143 & 731 & 965 & 665 & 260 \\
\hline NON MIGAS & 5,174 & 5,078 & 4,829 & 5,490 & 4,672 & 4,529 & 5,044 & 5,161 & 1,838 \\
\hline NERACA PERDAGANGAN & 405 & -392 & -668 & -699 & $-1,114$ & $-2,052$ & $-3,485$ & $-3,007$ & $-1,215$ \\
\hline
\end{tabular}

Berdasarkan data dalam Tabel 1 di atas mayoritas impor Indonesia dari Australia lebih merupakan bahan baku atau bahan penolong industri, seperti gandum, batu bara, bijih besi, alumunium, seng, gula mentah, serta susu dan krim. ${ }^{26}$ Produk impor utama Indonesia dari Australia adalah 'gandum senilai USD 639,6 juta; batu bara senilai USD 632 juta; hewan hidup jenis lembu senilai USD 573,9 juta; gula mentah atau tebu lainnya senilai USD 314,7 juta; dan bijih besi dan bijih lainnya senilai USD 209,3 juta'.27 Terlepas dari fakta bahwa Indonesia mengalami defisit karena impor produk-produk di atas, data ini menarik untuk dicermati lebih lanjut. Mengapa? Ketika yang diimpor adalah bahan baku atau bahan penolong industri artinya produk-produk ini diolah menjadi produk lanjutan yang memiliki nilai tambah (value added) untuk memenuhi kebutuhan dalam negeri Indonesia.

Optimalisasi pengolahan lebih lanjut produk yang diimpor Indonesia dari Australia Indonesia dapat dilakukan berupa membuat produk lanjutan dari produk yang diimpor dengan tujuan untuk tidak hanya untuk memenuhi kebutuhan dalam negeri tetapi juga untuk diekspor ke negara lainnya (Kawasan Amerika Latin, Asia dan Pasifik, dan Uni Eropa). Secara teoritis, tentu tidak hanya terbatas pada kasus produk yang diimpor Indonesia dari Australia di atas. Lebih luas lagi ide reproduksi produk mentah yang diimpor diterapkan bagi barang industri lainnya. Konsep ini dikenal sebagai outward-oriented industrialization policy and export promotion seperti

26 Kementerian Perdagangan Republik Indonesia, 'Penyelesaian IA-CEPA Perlu Disambut Pelaku Usaha' (n 24)

27 Kementerian Perdagangan Republik Indonesia, 'Penyelesaian IA-CEPA Perlu Disambut Pelaku Usaha' (n 24) 
yang dilakukan Singapore, ${ }^{28}$ Hongkong, ${ }^{29}$ China $^{30}$ dan Taiwan ${ }^{31}$ dan Korea Selatan. ${ }^{32}$ Kini, secara teoritis, konsep industri berorientasi ekspor dalam skala besar dikenal juga sebagai economic powerhouse dimana sebuah negara bisa menjadi tempat untuk memproduksi secara besar-besaran atau menciptakan pabrik raksasa yang memproduksi barang dan jasa bagi kebutuhan dunia seperti yang telah dilakukan di China ${ }^{33}$ dan Korea Selatan. ${ }^{34}$ China, misalnya, hingga tahun 2001, sejak menerapkan konsep economic powerhouse, telah tumbuh menjadi negara dengan pertumbuhan ekspor tercepat di dunia. Ekspor China meningkat rata-rata 17\% yakni sebesar 13.7 Milliar US Dollar di tahun 1979 menjadi 266 Miliar US Dolar di tahun 2001.35 Belajar dari pengalaman China, Indonesia perlu juga membangun industri (pabrik) berskala besar berorientasi ekspor ataupun pasar luar negeri. Ini merupakan tantangan besar yang perlu dijawab oleh pemerintah dan kalangan pengusaha Indonesia.

Perhitungan yang dilakukan oleh Indonesia for Global Justice tahun 2019, potensi ekspor Indonesia ke Australia mencapai US \$ 201 juta sedangkan potensi ekspor Australia ke Indonesia mencapai US \$ 1 miliar. ${ }^{36}$ Karena itu selain memastikan peningkatan dan perluasan ekspor produk unggulan Indonesia ke Australia, perlu mencari peluang pasar baru di Australia agar ekspor Indonesia bisa digenjot. Jika tidak, defisit neraca perdagangan Indonesia terhadap Australia akan semakin mendalam. Dalam konteks ini, sekali lagi outward-oriented industrialization policy and export promotion atau economic powerhouse menjadi relevan untuk segera dilaksanakan secara akseleratif, sistematis dan berkesinambungan.

Kedua, dengan fasilitasi yang dilakukan oleh Pemerintah maupun mandiri, kalangan pengusaha perlu memetakan lagi sektor industri dan komoditas yang tidak unggul untuk diperbaiki dan ditingkatkan kualitas dan kuantitasnya (produksinya) untuk menghadapi banjirnya barang dan jasa unggulan dari Australia. Hal ini penting untuk menghindari ekses negatifnya bagi meningkatnya pengangguran dan merosotnya kepercayaan domestik atas produk-produk Indonesia. Ketiga, kalangan pengusaha, baik mandiri ataupun dengan fasilitas pemerintah, perlu mengidentifikasi berbagai hambatan perdagangan, baik jasa dan barang, tarif maupun non tarif yang dihadapi pihak Indonesia utamanya kalangan

Bruce E. Moon, 'Exports, Outward-Oriented Development, and Economic Growth' (1998) 51 (1) Political Research Quarterly 7, 7-36.

Fields G. S., 'Changing labor market conditions and economic development in Hong Kong, the Republic of Korea, Singapore, and Taiwan, China' (1994) 8 (3) World Bank Economic Review 395, 395-414.

30 Doaa Wafik and Assem Tharwat. 'China's Balance of Payments Evolution From Deficit to Sustainability Surplus' (2020) 1 (2) International Journal of Industry and Sustainable Development 49, 63; Nicola Meier, China-The New Developmental State? An Empirical Analysis of the Automotive Industry (Peter Lang GmbH lnternationaler Verlag der Wissenschaften Frankfurt am Main 2009) 53. Kishore G. Kulkarni and Qixiang Sun, 'Outward Looking Policies and Economic Development: A Case of Taiwan Since 1952' (2004) 5 (1) Global Business Review 14. Dilip K. Das, Outward-Oriented Industrialization Strategy, in Korean Economic Dynamism (Palgrave Macmillan 1991) 59-82. Tilak Abeysinghe and Ding Lu, 'China as an economic powerhouse: Implications on its neighbour's' (2003) 14 (2) China Economic Review 164, 185.

34 Cahrles Harvie and Hyun-Hoon Lee, 'Export-led Industrialisation and Growth: Korea's Economic Miracle, 1962-1989’ (2003) 43 (3) Australian Economic History Review 256, 286.

36 Arfandi and Hertanti (n 25) 
eksportir lalu segera mencarikan penyelesaiannya dengan pihak Australia. Hal ini dimaksudkan untuk menghindari hambatan-hambatan yang bisa menyumbang bagi ekonomi biaya tinggi yang pada akhirnya menurunkan tingkat atau daya kompetitif produk-produk Indonesia terhadap produk-produk Australia.

Keempat, kalangan pengusaha, baik mandiri maupun dengan fasilitas pemerintah, segera saja untuk mengidentifikasi dan menentukan sektor mana yang perlu ditindaklanjuti dalam kerja sama konkrit dalam jangka pendek, menengah dan panjang, serta membentuk atau memperkuat asosiasi atau apapun namanya untuk kegiatan ekspor-impor atas barang dan jasa strategik dari dan ke Australia. Kelima, pengusaha dan kalangan bisnis Indonesia perlu memahami hukum, bahasa dan budaya bisnis dan budaya umumnya di Australia. Kurang paham atau tidak paham atas hukum, bahasa dan budaya bisnis dan budaya umumnya di Australia atau yang saya sebut sebagai hambatan budaya ini menjadi pemicu kurang berhasilnya kerjasama ekonomi dan dagang. Tentu tidak hanya dengan Australia tetapi dengan negara manapun, hambatan budaya agar diperhatikan. Dalam konteks ini, cross culture understanding, hubungan swasta dengan swasta, hubungan perorangan, diplomasi budaya dan politik menjadi kunci dalam mendorong kemajuan investasi dan perdagangan antara kalangan pengusaha Indonesia dan Australia.

Selanjutnya Kementerian Pendidikan dan Kebudayaan dan perguruan tinggi (universitas) di Indonesia pada umumnya perlu memainkan peran strategisnya untuk mendorong dan menghasilkan kebijakan dan luaran (tamatan) perguruan tinggi yang mampu memenuhi kebutuhan keahlian (skill) oleh pasar domestik dan pasar luar negeri. Kementerian Pendidikan perlu juga memfasilitasi perguruan tinggi di Indonesia untuk meningkatkan kerjasama dalam hal pendidikan dan pelatihan terkait jurusan atau program studi kedokteran, ilmu komputer, dan informasi teknologi, akuntansi dan pembukuan, perhotelan dan restoran, kepariwisataan, pertanian dan perikanan. Langkah ini termasuk, jika diperlukan, melakukan benchmarking kurikulum dengan di Australia sehingga tamatan jurusan-jurusan ini bisa bekerja di Australia. Inilah yang dilakukan India, Malaysia, Singapore dan Filipina (khususnya tenaga dokter dan perawat) sehingga lulusan dari jurusan mereka bisa diterima di berbagai perusahaan atau dipekerjakan berbagai perusahaan dari atau di Australia, Amerika dan Uni Eropa, termasuk Uni Emirate Arab (Dubai).

Khusus untuk pendidikan vokasional, Kemendikbud (tentu dengan bekerja sama dengan Kementerian Perdagangan dan Kementerian Perindustrian) perlu memfasilitasi pendidikan vokasi (sekolah teknik atau politeknik). Catatan khusus perlu diberikan bagi sektor ini karena sejatinya kualitas pendidikan vokasi di Indonesia masih belum menjawab kebutuhan real industri (pasar). Oleh karenanya perlu mempertimbangkan pula antara lain benchmarking kurikulum dengan mitra di Australia, utamanya Technical Vocational, Education and Training (TVET) Australia yang sudah sangat maju dan meningkatkan pelatihan dan magang ke Australia maupun di Indonesia sendiri. Sekali lagi, Benchmarking kurikulum maupun kerjasama perguruan tinggi dan pendidikan vokasi menjadi pintu masuk yang perlu dipertimbangkan secara serius. Langkah strategis di atas dapat diawali Indonesia dengan secara akurat memetakan skill yang paling dibutuhkan di Australia, pasar domestik (Indonesia) dan pasar global lainnya dengan menyesuaikan kurikulum dan 
pelatihan konsisten dan professional atau bila perlu mereset pendidikan vokasi Indonesia untuk keperluan ini.

Saran di atas didasarkan pada perhitungan yang dilakukan oleh McKinsey Global Institute (MGI) bahwa di tahun 2030 Indonesia akan membutuhkan 113 juta tenaga kerja berkeahlian (skilled workers). Ini merupakan peningkatan drastis dari 57 juta skilled workers di tahun 2016. Artinya terdapat kesenjangan besar dalam hal skilled workers supply di Indonesia. ${ }^{37}$ Masih menurut MGI, setiap tahunnya akan terdapat tambahan 3.7 juta skilled workers yang dibutuhkan. Untuk industri pariwisata saja saat ini mempekerjakan 12.8 juta orang dan diperkirakan akan meningkat menjadi 15 juta di tahun 2024. Dalam bidang industri digital Indonesia membutuhkan 9 juta skilled workers di tahun 2030.38

Australia terkenal memiliki reputasi yang sangat baik terkait penyediaan tenaga kerja berkeahlian dalam bidang hospitality: tourism, perhotelan, restoran. makanan, minuman, dan pertanian, perikanan, peternakan, dan pertambangan, termasuk creative industries: fashion, media dan sektor digital/informasi dan teknologi. Tetapi di saat bersamaan Australia mengalami kekurangan tenaga kerja dalam sejumlah bidang antara lain kelistrikan, tata rias/kecantikan dan salon, tata boga, keperawatan, pertanian, peternakan dan perikanan. The Australia Institute memperkirakan bahwa pada tahun 2030 Australia mengalami kekurangan tenaga kerja mencapai 2.3 juta tenaga kerja. ${ }^{39}$

Bagaimana mengisi skilled workers supply gap yang besar ini? Ada dua pilihan. Peningkatan pelatihan dan magang dalam sektor relevan untuk memenuhi kebutuhan pangsa pasar Australia dan Indonesia. Alternatif pertama, bisa saja Indonesia menggandeng sektor Technical Vocational, Education and Training (TVET) Australia yang memiliki kemampuan yang sudah teruji untuk melatih dan mendidik dan melakukan magang bagi calon skilled workers Indonesia. Cara pendidikan dan pelatihan magang bisa mengkombinasikan blended learning berupa offline maupun online kelas dan pelatihan.

Sebagai contoh konkrit, di atas telah disinggung bahwa gandum dan hewan hidup (termasuk sapi, domba dll) merupakan dua di antara import utama Indonesia dari Australia. Kita tahu produk mie berbahan gandum (masih langka) dan non gandum kini diminati di seluruh dunia, termasuk Afrika. Indonesia bisa memanfaatkan impor gandum untuk pembuatan mie berbahan gandum lalu mengekspor lagi ke kawasan dunia lainnya. Demikian pula, impor sapi dan lembu, bisa diolah lagi menjadi produk daging beku untuk diekspor ke Timur Tengah dan negara Asia dan Afrika Islam lainnya. Tentu dengan mengenakan label halal dari Indonesia, akan lebih mudah diterima di Kawasan Timur Tengah dan negara Islam lainnya di Asia dan Afrika. Melalui pendekatan economic powerhouse dan persiapan tenaga kerja dan pabrik dengan memanfaatkan kerjasama pelatihan dan pendidikan dari Australia, Indonesia bisa menjadi negara yang industrinya berorientasi ekspor. Tentu kedua contoh di atas bisa diaplikasikan ke jenis komoditas lainnya.

\footnotetext{
37 Department of Foreign Affairs and Trade Australia of Australia (n 2).

38 Department of Foreign Affairs and Trade Australia of Australia (n 2).

39 Boston Consulting Group 'Does Australia face a labour shortage?' (The Australia Institute, 2020) <https://www.tai.org.au/content/does-australia-face-labour-shortage-check-facts> diakses 10 Juli 2020.
} 
Alternatif kedua ialah ketika Indonesia melakukan benchmarking kurikulum pendidikan vokasi di sektor-sektor di atas dengan pendidikan vokasi Australia dengan modifikasi kurikulum yang dapat menghasilkan skill yang paling dibutuhkan Indonesia dan Australia. Namun dalam pelaksanaannya, tetap melibatkan quality control dari pihak Australia. Jika skenario ini berjalan, dalam jangka panjang Indonesia bisa mengekspor skilled workers dalam sektor-sektor di atas, tidak hanya ke Australia tetapi juga negara lainnya seperti Jepang, Uni Emirate Arab, dan Eropa. Tentu banyak manfaat yang bisa didapatkan oleh tenaga kerja Indonesia. Australia dan negara-negara di atas terkenal dengan upah buruh yang tinggi dan perlindungan buruh yang baik, termasuk jaminan kesehatan, jaminan hari tua dan skema pensiun yang jauh lebih memadai.

Masukan praktis lainnya ialah terkait dengan jaminan kepastian hukum, sinkronisasi/harmonisasi dan simplikasi hukum terkait dengan investasi dan perdagangan Harus diakui bahwa regulasi investasi Indonesia masih rumit. Hal ini terlihat dari data terbaru yang dirilis World Bank dimana Indonesia berada di peringkat 73 di antara 190 negara di tahun 2018 dan 2019 dari sisi kemudahan melakukan bisnis (the ease of doing business) (Grafik 1). Bahkan sebelumnya, di tahun 2016, International Monetary Fund (IMF) pernah menobatkan Indonesia sebagai negara urutan kedua dari 98 negara yang disurvey yang paling rumit bagi perusahaan multinasional untuk mematuhi regulasi yang berlaku dalam melalukan bisnis di Indonesia. 40

Grafik 1. Kemudahan berbisnis di Indonesia, 2010-201941

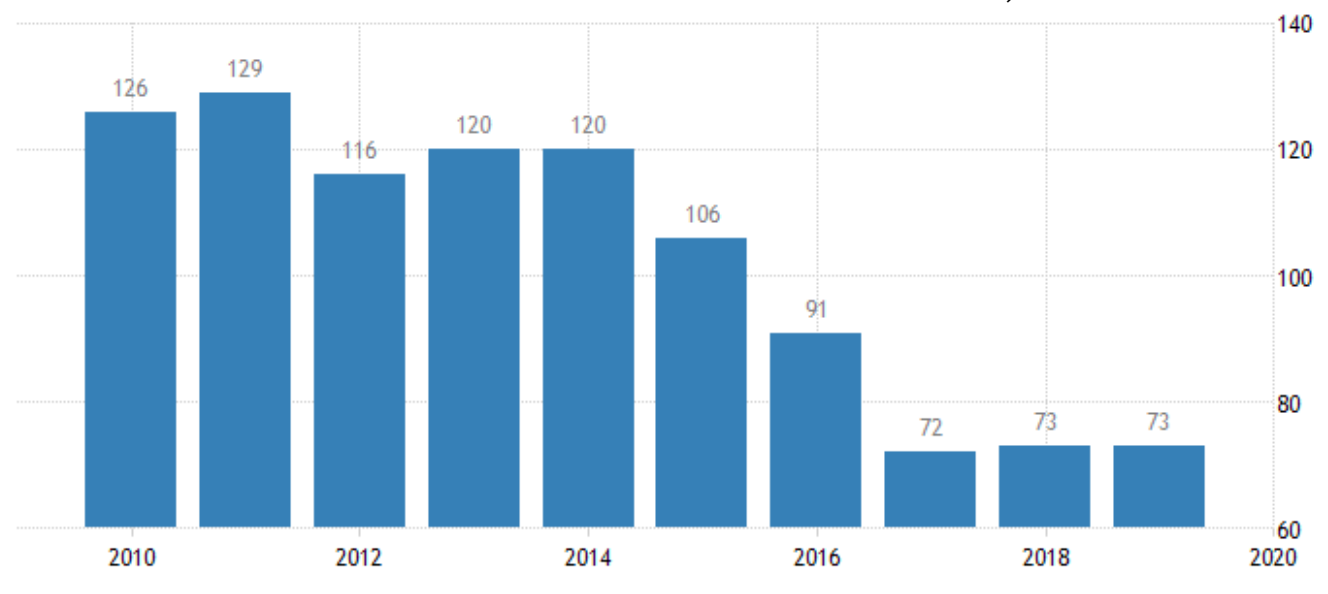

Tentu salah satu faktor yang membuat peringkat kemudahan berbisnis di Indonesia masih rendah ialah karena rumitnya regulasi, perizinan yang bertele-tele sehingga berbiaya tinggi dan ego-sectoral approach yang masih kuat. Untuk itu, Pemerintah cq BKPM dan kementerian perdagangan, perindustrian dan instansi terkait perlu memikirkan cara tercepat dan pendek untuk mengatasi isu ini. Kalau kerumitan berusaha ini tidak segera dituntaskan, IA-CEPA akan menghadapi

\footnotetext{
40 Mondaq, 'Indonesia Ranked The Second Most Complex Place For Business Compliance In The World' (Mondaq, 16 February 2016) <https://www.mondaq.com/compliance/470196/indonesia-ranked-the-second-most-complex-place-for-business-compliance-in-the-world> diakses 18 Juni 2020.

41 Trading Economics 'Ease of Doing Business in Indonesia' (Trading Economics, 2020) <https://tradingeconomics.com/indonesia/ease-of-doing-business> diakses 10 Juli 2020.
} 
masalah dimana pihak Australia kesulitan menyesuaikan dengan budaya hukum Indonesia yang rumit, bertele-tele, melelahkan dan mahal.

Untuk mengatasi regulasi yang rumit di atas, catatan perlu diberikan terkait berlakunya Undang-Undang No. 11 Tahun 2020 Tentang Cipta Kerja (selanjutnya disebut UU Cipta Kerja 2020). Terlepas dari kontroversi yang ditimbulkan, baik dari aspek teknis dan substantif, formal maupun material, sesuai salah satu tujuannya dalam Pasal 3 huruf b UU Cipta Kerja 2020 merupakan suatu langkah progresif untuk memotong mata rantai birokrasi perizinan yang rumit dan regulasi yang tumpang tindih, utamanya dalam bidang penanaman modal asing (foreign direct investment).

Langkah strategis yang perlu segera diperhatikan setelah berlakunya UU Cipta Kerja 2020, sesuai amanat Ketentuan Penutup, ialah membuat peraturan pelaksanaan lanjutan baik itu dalam bentuk Peraturan Pemerintah maupun dalam Peraturan Presiden yang konsisten dengan UU Cipta Kerja 2020 dan utamanya benar-benar memotong rumitnya birokrasi dan regulasi investasi, bisnis, dan kegiatan perekonomian lainnya. Langkah pentingnya lainnya ke depan ialah penegakan hukum yang tegas dan konsisten terkait substansi UU Cipta Kerja 2020 dan semua peraturan pelaksanaannya. Tanpa penegakan hukum yang tegas dan konsisten, UU Cipta Kerja 2020 tidak akan memberikan efek yang progresif dan positif bagi kemajuan investasi, pertumbuhan ekonomi dan peningkatan kesejahteraan masyarakat Indonesia.

Isu penting lainnya yang perlu dibenahi secara sangat fundamental ialah perubahan paradigma (sift paradigm) di kalangan birokrasi baik pusat dan daerah berupa perubahan mental, perilaku dan sistem birokrasi dari old traditional bureaucracy 42 menuju new-modern and servant bureaucracy and pro investment bureaucracy. Birokrasi tradisional yang lamban, berbelit-belit, dan mencari keuntungan dari perizinan investasi (bureaucratic rent-seeking) ${ }^{43}$ dan koruptif harus berubah menjadi mental dan perilaku birokrasi baru dan modern yang melayani, tanggap, efisien dan pro-investasi atau berjiwa kewirausahaan. ${ }^{44}$ Tanpa sift of paradigm dari kalangan birokrasi, perubahan regulasi investasi (apalagi tidak ada perubahan regulasi investasi yang pro pertumbuhan), rasanya sulit bagi Indonesia untuk memaksimalkan manfaat dan peluang ekonomi dan investasi dari IA-CEPA dan foreign direct investment yang dimimpikan hanya sebatas angan-angan.

42 Luc Bernier and Taïeb Hafsi, 'The Changing Nature of Public Entrepreneurship' (2007) 67(3) Public Administration Review 488, 493.

43 Ozay Mehmet, 'Rent-Seeking and Gate-Keeping in Indonesia: A Cultural and Economic Analysis' (1994) 27 (1) Labour, Capital and Society/Travail, Capital Et Société 56, 56-89; Andrew MacIntyre. Funny Money: Fiscal Policy, Rent-seeking, and Economic Performance in Indonesia in Jomo K.S. and Mushtaq Khan, Rent-Seeking in Southeast Asia (Cambridge University Press, Cambridge 2000) 248-273.

44 Mark D. Griffiths, Jill Kickul and Alan L. Carsrud, 'Government Bureaucracy, Transactional Impediments, and Entrepreneurial Intentions' (2009) 27(5) International Small Business Journal 626, 638; R. Donckels and A. Courtmans, 'Big Brother is Watching over You: The Counseling of Growing SMEs in Belgium' (1990) 2 (3) Entrepreneurship \& Regional Development 211, 224 ; O. Spilling. 'Entrepreneurship in a Cultural Perspective' (1991) 1(3) Entrepreneurship \& Regional Development 33, 48. 


\section{PENUTUP}

IA-CEPA berpotensi meningkatkan hubungan dagang Indonesia dan Australia ke jenjang yang lebih tinggi dan efisien. Luasnya cakupan kerja sama menuntut Indonesia agar berkerja keras dan bertindak strategik dan cepat untuk mengambil manfaat maksimal dari ditiadakannya hambatan tarif dan non-tarif dalam perdagangan barang dan jasa kedua negara.

Pemerintah (pusat) dan tentu juga perlu didukung DPR perlu secara proaktif dan konsisten mengkonsolidasi, mendukung dan memfasilitasi jaringan dan sumber daya nasional dan bersinergi dengan kalangan swasta untuk menjawab tantangan dan peluang dagang, investasi dan kerja sama ekonomi dengan pihak Australia.

Industri nasional perlu segera merealisasikan outward-oriented industrialization policy and export promotion ataupun economic powerhouse yang menjadikan pasar luar negeri, termasuk pasar Australia menjadi target dalam kegiatan produksinya. DPR dan pemerintah juga agar segera menyelesaikan pembahasan RUU Cipta Lapangan Kerja untuk memotong mata rantai kerumitan investasi di Indonesia. Sementara itu, perlu sift paradigm dalam perilaku dan mental birokrasi dari old traditional bureaucracy yang lambat dan koruptif menjadi new modern bureaucracy yang melayani dan bermental wirausaha. Sedangkan untuk kalangan pendidikan tinggi dan vokasi, benchmarking kurikulum dengan sektor TVET Australia merupakan pilihan yang rasional, di samping peningkatan magang dan pelatihan skilled workers baik Indonesia maupun di Australia.

Namun kiranya perlu diingat bahwa sebagai bagian dari free trade agreements, IA-CEPA juga berpotensi menghasilkan eksternalitas negatif bagi Indonesia seperti coordination externalities dimana Indonesia tidak mampu memanfaatkan peluang yang ada dan akibatnya tidak mampu mendapatkan manfaat maksimal perdagangan barang dan jasa dengan pihak Australia.

Dari aspek hukum, Pemerintah Indonesia perlu mempercepat harmonisasi hukum nasional yang terkait dengan substansi Perjanjian IA-CEPA sehingga tidak terjadi konflik hukum yang merugikan kepentingan nasional dan ekonomi Indonesia. Semoga Indonesia bisa memenangkan pertempuran dagang dan jasa dengan Australia dalam jangka panjang dan mendapatkan benefit maksimal. Jika tidak, tentu Indonesia akan semakin merana.

\section{DAFTAR REFERENSI}

\section{Buku}

Das DK, Outward-Oriented Industrialization Strategy, in Korean Economic Dynamism (Palgrave Macmillan 1991).

Grunberg IKI, Stern MA (eds.), Global public goods: international cooperation in the 21st century (UNDP Oxford University Press 1999).

Low P and A Yeats, Do 'Dirty' Industries Migrate? in Patrick Low, ed., International Trade and the Environment; World Bank Discussion Papers (Washington, DC: World Bank 1992).

Lukas K and Steinkellner A, Social Standards in Sustainability Chapters of Bilateral Free Trade Agreements (Ludwig Boltzmann Institute of Human Rights 2010). 
MacIntyre A, Funny Money: Fiscal Policy, Rent-seeking, and Economic Performance in Indonesia in Jomo K.S. and Mushtaq Khan, Rent-Seeking in Southeast Asia (Cambridge University Press, Cambridge 2000).

Meier N, China-The New Developmental State? An Empirical Analysis of the Automotive Industry (Peter Lang $\mathrm{GmbH}$ lnternationaler Verlag der Wissenschaften Frankfurt am Main 2009).

Scott RE, Unfair trade deals lower the wages of U.S. workers (Economic Policy Institute, Washington DC 2015).

\section{Jurnal}

Abeysinghe $\mathrm{T}$ and $\mathrm{Lu} \mathrm{D}$, 'China as an economic powerhouse: Implications on its neighbour's' (2003) 14 (2) China Economic Review.

Bernier L and Hafsi T, 'The Changing Nature of Public Entrepreneurship' (2007) 67 (3) Public Administration Review.

Daquila T C and Huy L H, 'Singapore and ASEAN in the Global Economy, The Case of Free Trade Agreements' (2003) 43 (6) Asian Survey.

Donckels R and Courtmans A, 'Big Brother is Watching over You: The Counseling of Growing SMEs in Belgium' (1990) 2 (3) Entrepreneurship \& Regional Development.

Edge A R, 'Preventing So ware Piracy through Regional Trade Agreements: e Mexican Example' (1994) 20 (1) North Carolina Journal of International Law and Commercial Regulation.

Fields G S, 'Changing Labor Market Conditions And Economic Development in Hong Kong, the Republic of Korea, Singapore, and Taiwan, China' (1994) 8 (3) World Bank Economic Review.

Fietta S, 'Most Favoured Nation Treatment And Dispute Resolution Under Bilateral Investment Treaties: A Turning Point?' (2005) 4 International Arbitration Law Review.

Fischer R D and Serra P, 'Income Inequality and Choice of Free Trade in a Model of Intraindustry Trade' (1999) 111 (1) The Quarterly Journal of Economics.

Griffiths M D, Kickul J and Carsrud A L, 'Government Bureaucracy, Transactional Impediments, and Entrepreneurial Intentions' (2009) 27 (5) International Small Business Journal.

Harvie $\mathrm{C}$ and Lee $\mathrm{H}$, 'Export-led Industrialisation and Growth: Koreas's Economic Miracle, 1962-1989’ (2003) 43 (3) Australian Economic History Review.

Kulkarni K G and Sun Q, 'Outward Looking Policies and Economic Development: A Case of Taiwan Since 1952' (2004) 5 (1) Global Business Review.

Limao N and Saggi K, 'Size Inequality, Coordination Externalities And International Trade Agreements' (2013) 63 European Economic Review.

Lydgate E, 'Sorting Out Mixed Messages under the WTO National Treatment Principle: A Proposed Approach' (2016) 15 (3) World Trade Review. 
Mehmet O, 'Rent-Seeking and Gate-Keeping in Indonesia: A Cultural and Economic Analysis' (1994) 27 (1) Labour, Capital and Society/Travail, Capital Et Société.

Moon B E, 'Exports, Outward-Oriented Development, and Economic Growth' (1998) 51 (1) Political Research Quarterly.

Spilling O, 'Entrepreneurship in a Cultural Perspective' (1991) 1 Entrepreneurship \& Regional Development.

Wafik D and Tharwat A, 'China's Balance of Payments Evolution From Deficit to Sustainability Surplus' (2020) 1 (2) International Journal of Industry and Sustainable Development.

\section{Website}

Arfandi $\mathrm{H}$ and Hertanti $\mathrm{R}$, 'Analisis Kritis Kerjasama Indonesia-Australia CEPA: "Berpotensi Besar Meningkatkan Impor, Ketimbang Ekspor"' (Indonesia for Global Justice 2019) <http://igj.or.id/wp-content/uploads/2019/08/ KertasKebijakan-IGJ_Juli-2019_IA-CEPA-1.pdf> diakses 10 Juli 2020.

Boston Consulting Group 'Does Australia face a labour shortage?' (The Australia Institute, 2020) <https://www.tai.org.au/content/does-australia-face-labourshortage-check-facts> diakses 10 Juli 2020.

Department of Foreign Affairs and Trade Australia of Australia, 'Indonesia - Australia Comprehensive Economic Partnership Agreement (IA-CEPA): Economic Cooperation Program (ECP)' (Department of Foreign Affairs and Trade Australia of Australia, May 2020) <https://www.dfat.gov.au/sites/default/files/ investment-design-ia-cepa-ecp-may-2020-web-vers.pdf> diakses 10 Juli 2020.

Kementerian Perdagangan Republik Indonesia, 'Penyelesaian IA-CEPA Perlu Disambut Pelaku Usaha' (Kementerian Perdagangan Republik Indonesia, 24 Oktober 2019) <https://www.kemendag.go.id/id/newsroom/media-corner/ penyelesaian-ia-cepa-perlu-disambut-pelaku-usaha-1> diakses 10 Juli 2020.

Medina A F, 'Indonesia and Australia Ratify IA-CEPA Agreement' (ASEAN Briefing, 14 Februari 2020) <https://www.aseanbriefing.com/news/indonesiaaustralia-ratify-ia-cepa-agreement/> diakses 12 Juli 2020.

Mondaq, 'Indonesia Ranked The Second Most Complex Place For Business Compliance In The World' (Mondaq, 16 February 2016) <https://www.mondaq.com/compliance/470196/indonesia-ranked-thesecond-most-complex-place-for-business-compliance-in-the-world > diakses 18 Juni 2020.

Parliament of Australia. Report 186, '3. IA-CEPA Benefits' (Parliament of Australia, 2009) <https://www.aph.gov.au/Parliamentary_Business/Committees /Joint/ Treaties/Indonesia-AustraliaCEPA/Report_186> diakses 10 Juli 2020.

Susanto V Y, 'IA-CEPA berlaku, ekonom CORE berharap Indonesia bisa kerek ekspor ke Australia' (Kontan, 11 Juli 2020) < https://nasional.kontan.co.id/news/iacepa-berlaku-ekonom-core-berharap-indonesia-bisa-kerek-ekspor-keaustralia> diakses 12 Juli 2020. 
Trading Economics 'Ease of Doing Business in Indonesia' (Trading Economics, 2020) $<$ https://tradingeconomics.com/indonesia/ease-of-doing-business $>$ diakses 10 Juli 2020.

World Bank, 'GDP per capita (current US\$) - Singapore' (The World Bank, 1999) <https://data.worldbank.org/indicator/NY.GDP.PCAP.CD?locations=SG> diakses 10 Juli 2020.

\section{Perjanjian Perdagangan Bebas Bilateral dan Regional}

ASEAN, 'Agreement Establishing The ASEAN-Australia-New Zealand Free Trade Area (AANZFTA)' <https://www.asean.org/storage/images/2013/economic/afta/AANZFTA/Ag reement\%20Establishing\%20the\%20AANZFTA.pdf> diakses 10 Juli 2020.

Department of Foreign Affairs and Trade of Australia, 'Indonesia-Australia Comprehensive Economic Partnership Agreement. IA-CEPA text and associated document' <https://www.dfat.gov.au/trade/agreements/in-force/iacepa/ iacepa-text/Pages/default> diakses 10 Juli 2020.

Kementerian Perdagangan Republik Indonesia 'IA-CEPA Lampiran 2-A Jadwal Komitmen Tarif Australia' (Direktorat Jenderal Perundingan Perdagangan Internasional <http://ditjenppi.kemendag.go.id/assets / files/publikasi/doc_20191203_2aaustralia-tariff-schedule-bahasa.pdf> diakses 10 Juni 2020.

Kementerian Perdagangan Republik Indonesia 'IA-CEPA Lampiran 2-A Jadwal Komitmen Tarif Indonesia' (Direktorat Jenderal Perundingan Perdagangan Internasional <http://ditjenppi.kemendag.go.id/assets/files/publikasi/doc_20191203_2aindonesia-tariff-schedule-bahasa.pdf> diakses 10 Juni 2020.

Kementerian Perdagangan Republik Indonesia, 'Chile - Indonesia Comprehensive Economic Partnership Agreement' <http://www.sice.oas.org/trade/CHL_IDN/CEPA_Index_e.asp> diakses 10 Juli 2020.

Kementerian Perdagangan Republik Indonesia, 'Indonesia-Pakistan Preferential Trade Agreement' <https://e-ska.kemendag.go.id/uploads/ lampiran_surat_IP_PTA.pdf> diakses 10 Juli 2020.

World Trade Law, 'ASEAN Free Trade Agreements (AFTA)' <http://www.worldtradelaw.net/fta/agreements/afta.pdf.download> diakses 20 Juli 2020.

\section{Peraturan Perundangan-Undangan}

Undang-Undang Nomor 1 Tahun 2020 tentang Pengesahan Persetujuan Kemitraan Ekonomi Komprehensif Indonesia - Australia (Indonesia - Australia Comprehensive Economic Partnership Agreement).

Undang-Undang Nomor 11 Tahun 2020 tentang Cipta Kerja. 
Peraturan Menteri Perdagangan Republik Indonesia Nomor 03 Tahun 2020 tentang Perubahan Atas Peraturan Menteri Perdagangan Nomor 110 Tahun 2018 tentang Ketentuan Impor Besi Atau Baja, Baja Paduan, dan Produk Turunannya. 